IIIIIIIIIIIIIIIIIIIIIIIIIIIIIIIIIIII

Original Article

IIIIIIIIIIIIIIIIIIIIIIIIIIIIIIIIIII

\title{
Performance evaluation of lysimeter experiments for simulating pesticide dissipation in paddy fields. Part 1: Submerged application of granular pesticides
}

\author{
Kei Kondo, ${ }^{1, *}$ Yoshiki Wakasone, ${ }^{1}$ Junichi OKuno, ${ }^{2}$ Naoki Nakamura, ${ }^{2}$ \\ Tetsuro Muraoka, ${ }^{2}$ Kazuaki IIjIma ${ }^{1}$ and Kazutoshi Ohyama ${ }^{1}$ \\ ${ }^{1}$ The Institute of Environmental Toxicology, 4321 Uchimoriya-machi, Joso-shi, Ibaraki 303-0043, Japan \\ ${ }_{2}^{2}$ Japan Association for Advancement of Phyto-Regulators, 860 Kashiwada-Cho, Ushiku-shi, Ibaraki 300-1211, Japan
}

(Received August 10, 2018; Accepted November 13, 2018)

\begin{abstract}
Three-year comprehensive experiments were conducted to compare the dissipation patterns of a total of 16 pesticides, including 3 metabolites, as granular formulations applied in lysimeters and paddy fields with two soil types. Analytical concentrations of the target pesticides in paddy water were analyzed using a granular kinetic model consisting of the following parameters: release rate, decrease rate, and dissolved concentration. Results of parameter grouping analyses of the kinetic models showed that $56 \%$ of data reproducibility (entire grouping) was obtained between replicates for the lysimeters. In comparisons between the lysimeters and paddy fields, $48 \%$ of decrease rates and $34 \%$ of release rates were grouped, although significant differences were observed with a nearly $90 \%$ difference for dissolved concentrations. These differences might be attributed to the hydrological components such as water management and meteorological covariates in paddy fields, the daily percolation in lysimeters and the adsorption-desorption kinetics between paddy water and soil. @ P Pesticide Science Society of Japan

Keywords: paddy pesticides, granular formulation, dissipation, flooded lysimeter, paddy field, kinetic model.
\end{abstract}

Electronic supplementary materials: The online version of this article contains supplementary materials (Supplemental Figs. S1-S2, Tables S1-S13), which is available at http://www.jstage.jst.go.jp/browse/jpestics/

\section{Introduction}

In Japan, rice cultivation is the main production component in the agricultural sector, with a cultivated area of approximately $54.4 \% .^{1)}$ Pesticide use in rice cultivation has been fundamental to the efficient control of pests, weeds, and diseases, thereby resulting in stable cultivation yields and high-quality products. Additionally, the recent advancement of pesticide formulation has allowed farmers to choose pesticide application methods and consequently save on labor. However, pesticides applied to paddy fields are more likely to be released into the open environment because they are applied directly to paddy water. ${ }^{2)}$ Hence, there has still been concern about pesticide contamination in public water areas, and various monitoring studies of pesticides have detected paddy pesticides in rivers on a nationwide scale during the rice cultivation season. ${ }^{3-6)}$ These reports indicated a similar trend where pesticide distribution was strongly affected by the application schedule and method in

\footnotetext{
* To whom correspondence should be addressed.

E-mail: kondoh@iet.or.jp

Published online January 19, 2019

(c) Pesticide Science Society of Japan
}

paddy fields. Therefore, it is important to understand the dissipation characteristics of pesticides in paddy fields under various usage scenarios.

In Japan, lysimeters have been popularly used as a simulator of paddy fields for investigating the fate and transport of pesticides under flooded conditions. Flooded lysimeter (hereafter denoted as lysimeter) monitoring has many advantages, such as multiple replications, a stable water balance condition without unintentional disturbance owing to meteorological events, and applicability for various scenarios. Previous studies using lysimeters have reported that the water solubility of herbicides was associated with its potential for surface runoff ${ }^{7)}$ and leaching. ${ }^{8)}$ Recently, a micro paddy lysimeter, which can run multiple experiments per year, has been developed to investigate pesticide fate and transport under controllable experimental conditions. ${ }^{9}{ }^{10)}$ For regulatory aspects, the registration of paddy pesticides in Japan requires the results of its dissipation in lysimeters to compute the tier 2 short-term predicted environmental concentration (PEC) for the risk assessment of drinking water safety and its effect on aquatic organisms. ${ }^{11)}$ Indeed, most dissipations of registered pesticides have been evaluated by lysimeter experiments. However, there is still a lack of knowledge regarding the applicability of lysimeter monitoring for predicting the dissipa- 


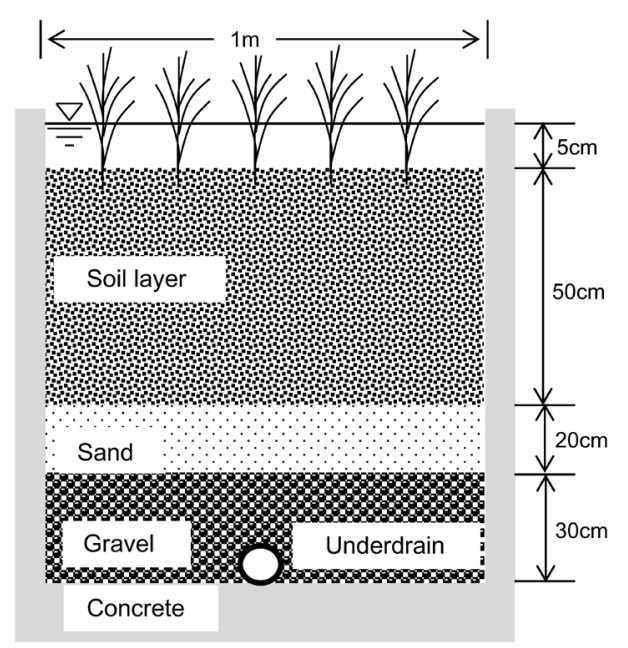

Fig. 1. Structure of flooding lysimeter: Each lysimeter has a surface area of $1 \mathrm{~m}^{2}$ and $1 \mathrm{~m}$ deep surrounded by concrete and contains alluvial or volcanic ash soil, sand and gravel from top to bottom.

tion of paddy pesticides in actual paddy fields with numerous variation factors, i.e., the type of formulation and its application method, the physicochemical properties of active ingredient, water balance, type of soil in the field, etc. Thus, a comprehensive monitoring study to compare the dissipation characteristics of pesticides in lysimeters and paddy fields under test conditions following the standard test guideline published in Japan is necessary.

Over multiple years, we conducted comparative monitoring studies in lysimeters and paddy fields to investigate the environmental fates of various paddy pesticides under similar test conditions with respect to pesticide formulation, application amount, and soil types, and then evaluated the lysimeter as an experimental tool for simulating actual conditions. The present paper compared the dissipation rates of a total of 16 pesticides, including 3 metabolites, applied in lysimeters and paddy fields for the submerged application of granular formulations. A companion paper ${ }^{12)}$ focused on the nursery box and foliar applications. Within the two study reports, relevant information, such as analytical methods and data processing, is also available in supplemental materials.

\section{Materials and Methods}

\section{Experiments}

Four-year continuous experiments on the dissipations of paddy pesticides in lysimeters and paddy fields were conducted with the same application dates and sampling schedule from 2012 to 2015. The basic experimental designs of both experiments followed the guideline published by the Ministry of Agriculture, Forestry and Fisheries of Japan. ${ }^{13)}$ The submerged applications of granular pesticides were conducted in 2012, 2014 and 2015. Details of the experiments are explained in the following sections. Note that the results of formulation IDs of B and C in 2012 and E in 2013 listed in Supplemental Table S2, applied as a nongranular formulation or different purpose, are not included in this paper and the results of the nursery-box application in 2013 and 2014, and the foliar application in 2015 are available in the companion paper. ${ }^{12)}$

\subsection{Experimental design of lysimeters}

The lysimeter experiments were conducted in outdoor lysimeters at the experimental facilities of the Institute of Environmental Toxicology (IET, Ibaraki, Japan). Each lysimeter had a surface area of $1 \mathrm{~m}^{2}$ and depth of $1 \mathrm{~m}$ surrounded by concrete and contained soil $(0-50 \mathrm{~cm})$, sand $(50-70 \mathrm{~cm})$, and gravel $(70-$ $100 \mathrm{~cm}$ ) from the top to the bottom, as shown in Fig. 1. Two kinds of soil groups-gray lowland soils (alluvial soil) and wet andosols (volcanic ash soil), which are widely distributed in Japanese agricultural fields-were packed in the soil layer and the experiment was performed using two of these lysimeters for each test compound. The physicochemical properties of the soils are summarized in Table 1. To prevent the overflow of paddy water due to precipitation, all lysimeters were covered with roof panel-penetrating UV radiation at a height of 3.0 (back) $-3.5 \mathrm{~m}$ (front) from the ground. The penetration efficiency of UV radiation (wavelength: $310-400 \mathrm{~nm}$ ) in the experimental periods ranged from 71.5 to $75.4 \%$, as measured using a UV radiometer UVR-1 (Topcon Technohouse Corporation, Tokyo, Japan).

During the experimental periods, the components of daily water balance-such as percolation, irrigation, evapotranspiration, and paddy water depth-in each lysimeter were recorded. Because there is no hard-pan layer, the lysimeter is not able

Table 1. Physicochemical properties of soils in experimental plots

\begin{tabular}{lcccc}
\hline \multicolumn{1}{c}{ Soil type } & Lysimeter & & Paddy field \\
\hline Texture (ISSS) & Alluvial & Volcanic ash & Alluvial & Volcanic ash \\
Organic carbon content (\%) & SCL & SiL & LiC & LiC \\
Soil pH ( $\left.\mathrm{H}_{2} \mathrm{O}\right)$ & 1.82 & 8.73 & 2.31 & 5.26 \\
Cation exchange capacity $\left(\mathrm{cmol}_{\mathrm{c}} / \mathrm{kg}\right)$ & 4.5 & 4.7 & 3.0 & 5.8 \\
Sand (\%) & 16.5 & 35.0 & 40.3 & 28.9 \\
Silt (\%) & 55.7 & 44.5 & 31.3 & 40.6 \\
Clay (\%) & 17.3 & 24.5 & 28.4 & 27.8 \\
\hline
\end{tabular}

These data were the analytical results of the soil samples homogeneously collected from the individual experimental plots. 
to maintain a flooding condition with a constant percolation rate under the natural drainage condition from the underdrain. Therefore, the daily percolation rate was artificially controlled to be $1.5 \mathrm{~cm} /$ day by collecting the percolating water from the closed underdrain using peristaltic pumps (SMP-21) and PharMed BPT tubing $(\varphi 3.15 \mathrm{~mm})$ purchased from Tokyo Rikakikai Co., Ltd. (Tokyo, Japan). The water requirement was observed as the water depth at around 9:00 a.m. to 9:30 a.m. on a daily basis. Evapotranspiration (ET) was calculated from the water requirement and percolation rate estimated from the amount of percolating water. Irrigation water pumped from the groundwater was supplied to set the water depth at $5 \mathrm{~cm}$. The maximum-minimum temperatures, relative humidity, and water temperature were also recorded daily. Additionally, the $\mathrm{pH}$ of the paddy water was also measured using a model F-72 $\mathrm{pH}$ meter (Horiba Ltd., Kyoto, Japan) each sampling day.

In 2012, two lysimeter replicates with standard experimental design were installed to evaluate the reproducibility of dissipation data and labeled as LA-S1 and -S2 for alluvial soil and LV-S1 and -S2 for volcanic ash soil plots. In 2013, a set of lysimeters with standard experimental design labeled as LA/LV-S was installed. In 2014, two sets of lysimeters, one for the standard experimental design and the other for the bare ground labeled as LA/LV-S and -B, respectively, were used. The LA/LV-B plots were installed to compare the behavior of the nursery box with the application of submerged and transplanted pesticide. In 2015, to evaluate the effect of artificial percolation as described in the previous paragraph, in addition to the set of standard plots (labeled LA/LV-S), a set of lysimeters used for zero percolation (no pumping from the underdrain) was prepared and labeled as LA/LV-Z. Note that a set of lysimeters for foliar application, labeled as LA/LV-F plots, was additionally prepared in 2015; a detailed explanation is available in the companion paper. ${ }^{12)}$ The plot design and abbreviations throughout the 4-year experiment are available in Supplemental Fig. S1 and Supplemental Table S1, respectively.

\subsection{Experimental design of the paddy fields}

The field experiments were carried out in two experimental paddy fields of the Japan Association for Advancement of PhytoRegulators (JAPR, Ibaraki, Japan) located within $30 \mathrm{~km}$ of the IET lysimeter facilities. The layouts of two fields are shown in Fig. 2. Both fields had $800 \mathrm{~m}^{2}$ surface areas with alluvial and volcanic ash soils that were the same as the soil types of the lysimeters (hereafter labeled FA for alluvial soils and FV for volcanic ash soils, Table 1$)$. The polycarbonate borders ( $30 \mathrm{~cm}$ wide) were installed with a depth of $10-15 \mathrm{~cm}$ around the levees of both fields to prevent overflow and lateral seepage. The scaffolds were embedded after transplantation. Six porous cups were installed near the scaffolds of both plots after transplantation to collect the soil water at depths of 15 and $30 \mathrm{~cm}$ from the soil surface in 2012 and 2013. Note that polyvinyl chloride pipes were additionally embedded as culverts in the center and the irrigation pump side of the FV plot to analyze the culvert water in 2014.

For water management in both fields, the water depth was (a)

(b)
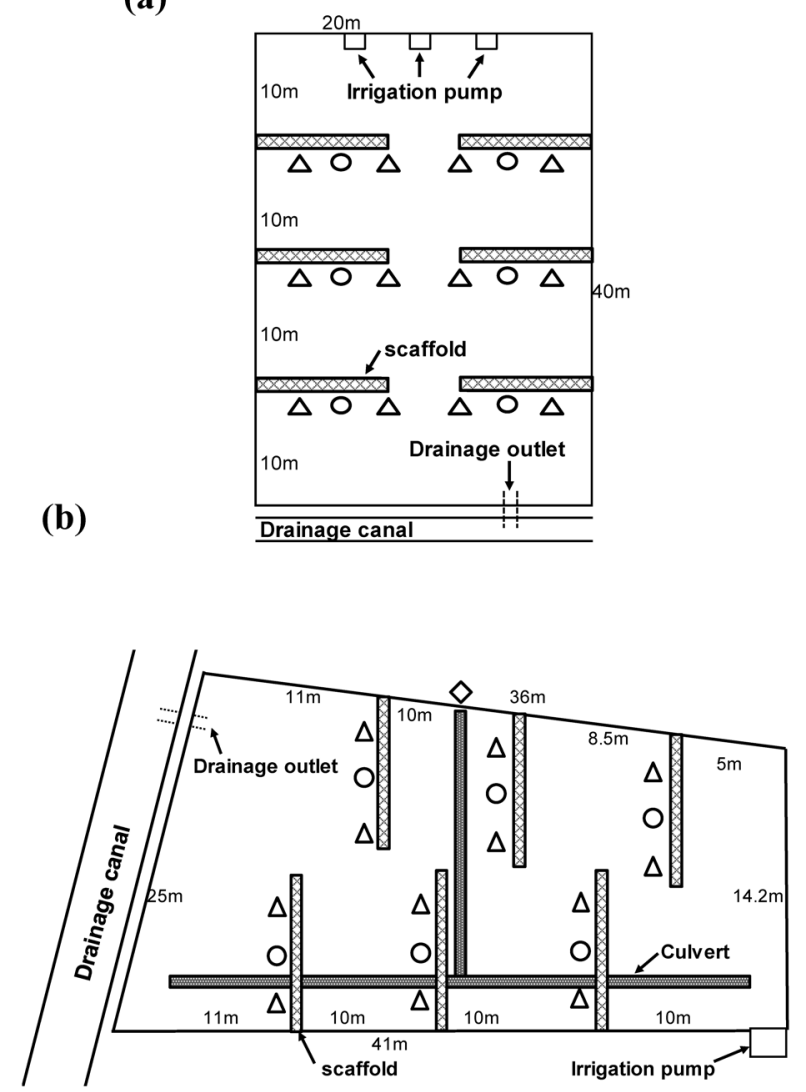

Fig. 2. Layouts of experimental paddy fields. (a) FA plot; (b) FV plot; $(\triangle)$ sampling point of paddy water; $(\bigcirc)$ install position of porous cup and sampling point of soil water; $(\diamond)$ sampling point of culvert water.

observed at twelve points corresponding to the water sampling points, and their average values were recorded on sampling days and days when intensive rainfall events occurred. The water requirements were estimated as the cumulative decrease of water depth between observations. To maintain a water depth of approximately $5 \mathrm{~cm}$, water was pumped from an irrigation canal. The meteorological values, such as temperature, humidity, and precipitation in each field, were also recorded using a Vantage Pro2 (Davis Instruments, Ca, USA.) on a daily basis. Additionally, water temperature and $\mathrm{pH}$ were also measured at each sampling day. The daily ET was estimated using the FAO PenmanMonteith method ${ }^{14)}$ calibrated for rice crops. ${ }^{15,16)}$ In addition to the recorded meteorological values described above, the forecasted values, such as average wind velocity and solar radiation at Tsukuba or Ryugasaki (Ibaraki, Japan) provided by Japan Meteorological Agency were used for the calculation. Finally, the daily percolation rate estimated from the water requirement and ET was linearly extrapolated between observed days.

\subsection{Pesticide application and sampling}

Table 2 summarizes the commercial granular products, their active ingredients targeted in this study, their application dates, and the application rates used in this study. The theoretical maximum concentrations of target pesticides $\left(C_{\max }\right)$, calculated 
under the assumption that all applied pesticides are dissolved in paddy water with a $5 \mathrm{~cm}$ ponding depth, are also listed in Table 2. The complete list of applied formulation products and the physicochemical properties of active ingredients throughout the study are found in Supplemental Tables S2 and S3, respectively. The applied commercial granular products in 2012, 2014, and 2015 were aimed to monitor the behaviors of the pesticides at the tillering, transplanting, and booting stages of the rice cultivation season, respectively. The portions of target granular formulations were applied by hand to the lysimeters and paddy fields at the recommended rate on the same date (see Table 2).

For the lysimeter experiments, paddy water samples were taken from nine points using glass syringes and transferred into glass bottles 0 (before application), $0.125,1,2,3,5,7,8,10$, 14 , and 21 days after treatment (DAT). Similarly, the percolating water samples were taken from the collected tanks 0 (before application), 7, 14, and 21 DAT. Both water samples were immediately subjected to chemical analysis after the sampling. For the paddy field experiments, paddy water samples were taken from the sampling points shown in Fig. 2 using glass syringes and transferred into glass bottles separately at the same sampling schedule on the lysimeter experiments. Note that as additional sampling of paddy water at 0.25 DAT in 2015 was conducted. The soil waters were collected in Erlenmeyer flasks by vacuum pumps and transferred to glass bottles on each sampling day. All sampled glass bottles were tightly capped and transported to the IET analytical facility in cool and light-proof conditions. Note that the analytical results of the percolating water in the lysimeters, soil wate, $r$ and culvert water in the paddy fields were not forecasted in this study, and these results are found elsewhere. ${ }^{17)}$

\subsection{Chemical analysis}

1.4.1. Analytical standard and reagents

The analytical standards (chemical purity: 98.9-100\%) were purchased from FUJIFILM Wako Pure Chemical Corporation (Osaka, Japan) and Hayashi Pure Chemical Industries, Ltd. (Osaka, Japan). Pesticide analysis-grade and LC/MS-grade acetonitrile and analytical-grade ammonium acetate and formic acid were purchased from FUJIFILM Wako Pure Chemical Corporation. HPLC-grade tetrahydrofuran was purchased from Kanto Chemical Industries (Tokyo, Japan). Water used for the experiments was purified using a PURELAB Flex System (Veolia Water Solutions \& Technologies, Saint-Maurice, France).

1.4.2. Cleanup procedure of water samples

Water samples from both fields were received in the IET analytical facility one day after each sampling day. Equal volumes of the water samples obtained from the same plot were combined, and then subjected to chemical analysis. All water samples for the lysimeters and paddy fields were analyzed in duplicate.

In 2012, a $100 \mathrm{~mL}$ water sample was acidified by adding $2.5 \mathrm{~mL}$ of formic acid and passed through a styrene-divinylbenzene cartridge $(500 \mathrm{mg} / 6 \mathrm{~mL}$, InertSep PLS-2; GL Sciences, Tokyo, Japan) preconditioned with $5 \mathrm{~mL}$ of acetonitrile and water. The cartridge was washed with $10 \mathrm{~mL}$ of acetonitrile: water (20:80, v/v) and the eluate was discarded. Pesticides were eluted with $10 \mathrm{~mL}$ of acetonitrile and $5 \mathrm{~mL}$ of tetrahydrofuran. These eluates were collected in a $20 \mathrm{~mL}$ volumetric flask and made up to acetonitrile: tetrahydrofuran: water $(50: 25: 25$, $\mathrm{v} / \mathrm{v} / \mathrm{v}$ ) as the test solution. In 2014 and 2015, a $20 \mathrm{~mL}$ water sample was acidified with $0.5 \mathrm{~mL}$ of formic acid and loaded to the styrene-divinylbenzene cartridge. The cartridge was washed in $5 \mathrm{~mL}$ of $2.5 \%$ formic acid, and $20 \mathrm{~mL}$ of acetonitrile was passed

Table 2. Application detail of granule formulations and theoretical maximum concentrations of target pesticides

\begin{tabular}{|c|c|c|c|c|}
\hline Year & Date of application & Formulation product, Applicate rate & Pesticide [Metabolite] & $C_{\max }^{a)}(\mathrm{mg} / \mathrm{L})$ \\
\hline \multirow[t]{3}{*}{2012} & \multirow{3}{*}{$\begin{array}{l}\text { 11-June, Lysimeter }(12)^{b)} ; 10: 00-10: 30 \\
\text { Field }(20)^{b)} ; 14: 30^{c}, 13: 30^{d)}\end{array}$} & \multirow[t]{3}{*}{ MAMET SM $^{\circledR} \mathrm{GR}, 3 \mathrm{~kg} / 10 \mathrm{a}$} & Simetryn & 0.9 \\
\hline & & & Molinate & 4.8 \\
\hline & & & MCPB-ethyl (MCPB) & 0.48 \\
\hline \multirow[t]{6}{*}{2014} & \multirow{6}{*}{$\begin{array}{l}\text { 10-June, Lysimeter }(0)^{b)} ; 10: 00-10: 30 \\
\text { Field }(0)^{b)} ; 10: 30^{c)}, 14: 00^{d)}\end{array}$} & \multirow[t]{4}{*}{ BIGSURE $^{\circledR}$ ACE GR, $1 \mathrm{~kg} / 10 \mathrm{a}$} & Imazosulfuron & 0.18 \\
\hline & & & Daimuron & 0.9 \\
\hline & & & Fentrazamide & 0.6 \\
\hline & & & Bromobutide [Bromobutide-desbromo] & 1.8 \\
\hline & & \multirow[t]{2}{*}{$\mathrm{ST}^{\mathrm{BARRAGE}}{ }^{\circledR} \mathrm{GR}, 3 \mathrm{~kg} / 10 \mathrm{a}$} & Dimethametryn & 0.06 \\
\hline & & & Pretilachlor & 1.2 \\
\hline \multirow[t]{7}{*}{2015} & \multirow{7}{*}{$\begin{array}{l}\text { 15-July, Lysimeter }(47)^{b)} ; 10: 00-10: 30 \\
\left.\text { Field }(47)^{b)} ; 11: 00^{c}\right), 12: 00^{d)}\end{array}$} & \multirow[t]{2}{*}{ ARASHI STARKLE ${ }^{\circledR} \mathrm{GR}, 3 \mathrm{~kg} / 10 \mathrm{a}$} & Dinotefuran & 1.002 \\
\hline & & & Orysastrobin [5Z-orysastrobin] & 1.32 \\
\hline & & \multirow[t]{2}{*}{ WIDEATTACK ${ }^{\mathrm{TM}} \mathrm{GR}, 1 \mathrm{~kg} / 10 \mathrm{a}$} & Daimuron & 2 \\
\hline & & & Penoxsulam & 0.12 \\
\hline & & \multirow[t]{3}{*}{ LONGKICK $^{\circledR}$ GR, $1 \mathrm{~kg} / 10 \mathrm{a}$} & Clomeprop [Clomeprop metabolite B] & 0.9 \\
\hline & & & Fentrazamide & 0.6 \\
\hline & & & Bensulfuron-methyl & 0.102 \\
\hline
\end{tabular}

a) Theoretical maximum concentration defined as applied pesticide is dissolved in paddy water with $5 \mathrm{~cm}$ ponding depth. ${ }^{b}$ Days after transplanting. ${ }^{c)}$ Application time at alluvial soil paddy field (FA Plot). ${ }^{d)}$ Application time at volcanic ash soil paddy field (FV Plot). 
through for the elution of pesticides. The eluate was corrected to a round-bottom flask and evaporated to dryness using a rotary evaporator and nitrogen blowdown apparatus. The residue was dissolved in $2 \mathrm{~mL}$ of water: acetonitrile: formic acid (60:40:0.1, $\mathrm{v} / \mathrm{v} / \mathrm{v})$ to prepare the test solution.

\subsubsection{LC-MS and LC-MS/MS analysis}

A liquid chromatograph with mass spectrometry (LC/MS) system (1100 series, Agilent Technologies, Santa Clara, CA, USA) equipped with an electrospray ionization (ESI) interface was used to determine the amount of pesticides in 2012 and 2013 and their tandem (LC-MS/MS) system (ACQUITY UPLC and Quattro Premier XE, Waters. Corporation, Milford, MA, USA) was used in 2014 and 2015. The analytical columns used for LC-MS and LC-MS/MS were Inertsil ODS-3 $(2.1 \times 150 \mathrm{~mm}, 5 \mu \mathrm{m}$ particle size, GL Sciences) and AQUITY UPLC BEH C18 $(2.1 \times 100 \mathrm{~mm}$, $1.7 \mu \mathrm{m}$ particle size, Waters Corporation), respectively. Acetonitrile and $5 \mathrm{mmol} / \mathrm{L}$ ammonium acetate were selected as the mobile phase. The LC pump was set at a flow rate of $0.2 \mathrm{~mL} / \mathrm{min}$ and the gradient elution was programmed. The detailed parameters for LC-MS and LC-MS/MS analyses are summarized in Supplemental Table S4. The amount of each pesticide was determined using an external standard method. The standard solutions were obtained as mixtures of target pesticides by diluting each standard stock solution $(200 \mathrm{mg} / \mathrm{L})$, which were prepared from purity-corrected analytical standards using acetonitrile. In 2012, the standard solutions were prepared in a range of $0.001-$ $0.1 \mathrm{mg} / \mathrm{L}$ by dilution with acetonitrile:tetrahydrofuran: water $(50: 25: 25, \mathrm{v} / \mathrm{v} / \mathrm{v})$ and those in 2014 and 2015 were in range of $0.005-0.2 \mathrm{mg} / \mathrm{L}$ and $0.001(0.005)-0.1(0.2) \mathrm{mg} / \mathrm{L}$ (the values in parentheses were for dinotefuran and clomeprop metabolite $\mathrm{B}$, respectively), respectively, diluted with water:acetonitrile: formic acid $(60: 40: 0.1, \mathrm{v} / \mathrm{v} / \mathrm{v})$ to obtain a calibration curve. The limit of quantification (LOQ) was set at $0.001 \mathrm{mg} / \mathrm{L}$ and the limit of detection was $0.0005 \mathrm{mg} / \mathrm{L}$ throughout this study.

\subsection{Method validation}

To employ the analytical method described above in this study, precision and accuracy were evaluated by the recovery test of each pesticide spiked with water samples collected in the LA and LV plots before application. Before the experiments started, recovery tests were conducted at three dose levels in triplicate: LOQ, 50×LOQ, and the expected or exceeded highest concentration in paddy water. The results of the recovery test of pesticides at individual dose levels are summarized in Supplemental Table S5. All of the mean recoveries of target pesticides at three dose levels were in a range of $74-119 \%$, and their relative standard deviations (RSDs) $<15 \%$. Additionally, there was no interference peak observed around the retention time of each on chromatograms from the blank sample.

\section{Data analysis}

To estimate the time required for $50 \%$ dissipation $\left(D T_{50}\right)$ from the concentrations of target pesticides at individual experimental plots, the analytical concentrations in paddy water samples for all target pesticides at individual test plots were fitted to the appropriate kinetic model by nonlinear fitting routines. For the granular pesticide application, the concentration curve of each pesticide includes the simultaneous release of pesticide from granules and its dissipation. For this reason, the single first order (SFO) model for granules was coupled with another kinetic phase expressing the release from the granule (denoted as the SFOR model in this study ${ }^{18)}$ and given as

$$
\frac{d C}{d t}=v_{r}-k_{e} c \quad \text { with } \quad v_{r}=k_{r} C_{\mathrm{diss}} e^{-k_{r} t}
$$

where $C$ is the pesticide concentration in the paddy water, $v_{r}$ is the release term, $C_{\text {diss }}$ is the dissolved pesticide concentration, $k_{r}$ is the release rate from the granule, and $k_{e}$ is the decrease rate in the paddy water. The integral form of Eq. (1) is obtained as

$$
C_{t}=\frac{C_{\text {diss }} k_{r}}{k_{r}-k_{e}}\left(e^{-k_{e} t}-e^{-k_{r} t}\right)
$$

where $C_{t}$ is the pesticide concentration in the paddy water at time $t$. The fitted results between test plots with the same soil type were subjected to grouping analyses to compare entire groups for assessing the differences between test plots and comparing specific parameters $\left(C_{\mathrm{diss}}, k_{r}\right.$ and $\left.k_{e}\right)$ using one-way analysis of variance. ${ }^{19)}$ The former analysis was to compare differences between the lysimeters and the latter was used to compare the lysimeter and the paddy field.

The goodness of fit for the final model was evaluated visually and statistically. As a statistical measure, the $\chi^{2}$ test was used to evaluate the agreement between the calculated and observed values $^{20)}$ and is given as

$$
\chi^{2} \text { error }=100 \sqrt{\frac{1}{\chi_{\mathrm{tab}}^{2}} \cdot \sum \frac{(S-O)^{2}}{\bar{O}^{2}}}
$$

where $\chi_{\text {tab }}^{2}$ is the tabulated $\chi^{2}$ value with $m$ degree of freedom at the $5 \%$ significance level, $S$ is the simulated value, $O$ is the observed value and $\bar{O}$ is the mean of all observed values. Finally, the $D T_{50}$ was estimated from following equation

$$
D T_{50}=\frac{\ln 2}{k_{e}}
$$

All of the analyses were performed using statistical software $\mathrm{R}$ (ver.3.4.2, R Foundation for Statistical Computing) and a list of $\mathrm{R}$ functions used in this study is summarized in Supplemental Table S6. For analyses including metabolite compounds, such as MCPB-ethyl, bromobutide, orysastrobin, and clomeprop, the total concentration as a sum of the parent compound and its metabolite converted using the mass of the parent compound was used (expressed by placing "Total” before the compound name).

\section{Results}

\section{Water balance}

The monitored and calculated water balance components at individual experimental plots from 2012 to 2015 are shown in Table 3, and their daily variations at the FA and FV plots in the corresponding years are presented in Supplemental Fig. S2. 
Monitored data related to the water balance observation, other than those in Table 3, are summarized in Supplemental Table S7. The daily water depths in lysimeters were constantly maintained at $5 \mathrm{~cm}$ throughout the experiments using daily irrigation. However, in paddy fields, although average water depths were close to $5 \mathrm{~cm}$, their variation ranges were wide because of rainfall events and intermittent irrigation. Daily percolation rates in the lysimeters were within the range of $1-2 \mathrm{~cm}$ /day stipulated by the test guidelines. ${ }^{13)}$ In contrast, the daily percolation rates in paddy fields showed a relatively lower tendency, especially in the

Table 3. Summary of water balance data in experimental plots

\begin{tabular}{|c|c|c|c|c|}
\hline & \multicolumn{2}{|c|}{ Lysimeter } & \multicolumn{2}{|c|}{ Paddy field } \\
\hline & Alluvial & Volcanic ash & Alluvial & Volcanic ash \\
\hline \multicolumn{5}{|l|}{ Input $(\mathrm{cm})$} \\
\hline \multicolumn{5}{|c|}{ Irrigation } \\
\hline \multirow[t]{2}{*}{2012} & $33.8(1.6)^{a)}$ & $35.0(1.7)^{a)}$ & $5.8(0.3)$ & $9.0(0.4)$ \\
\hline & $37.5(1.8)^{a)}$ & $32.6(1.6)^{a)}$ & & \\
\hline 2013 & $37.2(1.8)^{a)}$ & $36.9(1.8)^{a)}$ & $5.2(0.2)$ & $11.2(0.5)$ \\
\hline \multirow[t]{2}{*}{2014} & $40.5(1.9)^{b)}$ & $38.8(1.8)^{b)}$ & $0.8(0.04)$ & $4.6(0.2)$ \\
\hline & $38.4(1.8)^{a)}$ & $38.5(1.8)^{a)}$ & & \\
\hline \multirow[t]{3}{*}{2015} & $49.9(2.4)^{a)}$ & $48.2(2.3)^{a}$ & $21.9(1.0)$ & $13.6(0.6)$ \\
\hline & $20.8(1.0)^{c)}$ & $15.0(0.7)^{c)}$ & & \\
\hline & $55.0(2.6)^{d)}$ & $49.2(2.3)^{d)}$ & & \\
\hline \multicolumn{5}{|c|}{ Precipitation } \\
\hline 2012 & 0.0 & 0.0 & 14.8 & 17.8 \\
\hline 2013 & 0.0 & 0.0 & 7.8 & 8.2 \\
\hline 2014 & 0.0 & 0.0 & 7.2 & 10.0 \\
\hline 2015 & 0.0 & 0.0 & 2.8 & 8.6 \\
\hline \multicolumn{5}{|c|}{ Output $(\mathrm{cm})$} \\
\hline \multicolumn{5}{|c|}{ Evaporation/Evapotranspiration } \\
\hline \multirow[t]{2}{*}{2012} & $3.7(0.14)^{a)}$ & $4.7(0.18)^{a)}$ & $6.9(0.33)$ & $7.1(0.31)$ \\
\hline & $6.5(0.25)^{a)}$ & $5.2(0.19)^{a)}$ & & \\
\hline 2013 & $6.4(0.29)^{a)}$ & $5.2(0.24)^{a)}$ & $6.8(0.32)$ & $6.7(0.34)$ \\
\hline \multirow[t]{2}{*}{2014} & $8.6(0.41)^{b)}$ & $7.6(0.36)^{b)}$ & $6.1(0.20)$ & $5.7(0.20)$ \\
\hline & $6.6(0.31)^{a)}$ & $7.3(0.35)^{a)}$ & & \\
\hline \multirow[t]{3}{*}{2015} & $18.5(0.88)^{a)}$ & $16.5(0.78)^{a)}$ & $11.4(0.40)$ & $11.4(0.40)$ \\
\hline & $20.8(0.99)^{c)}$ & $15.0(0.71)^{c)}$ & & \\
\hline & $24.0(1.14)^{d)}$ & $18.1(0.86)^{d)}$ & & \\
\hline \multicolumn{5}{|c|}{ Percolation } \\
\hline \multirow[t]{2}{*}{2012} & $31.2(1.49)^{a)}$ & $31.1(1.50)^{a)}$ & $9.0(0.43)$ & $14.6(0.54)$ \\
\hline & $31.0(1.48)^{a)}$ & $30.4(1.49)^{a)}$ & & \\
\hline 2013 & $31.2(1.46)^{a)}$ & $\left.31.8(1.51)^{a}\right)$ & $2.9(0.14)$ & $12.2(0.67)$ \\
\hline \multirow[t]{2}{*}{2014} & $31.9(1.52)^{b)}$ & $31.2(1.50)^{b)}$ & $1.3(0.09)$ & $7.1(0.41)$ \\
\hline & $31.9(1.52)^{a)}$ & $\left.31.2(1.50)^{a}\right)$ & & \\
\hline \multirow[t]{3}{*}{2015} & $31.4(1.50)^{a)}$ & $31.7(1.51)^{a)}$ & $12.1(0.58)$ & $11.3(0.54)$ \\
\hline & $0.0^{c)}$ & $0.0^{c)}$ & & \\
\hline & $31.0(1.48)^{d)}$ & $31.2(1.48)^{d)}$ & & \\
\hline \multicolumn{5}{|l|}{ Outflow } \\
\hline 2012 & 0.0 & 0.0 & 6.5 & 6.0 \\
\hline 2013 & 0.0 & 0.0 & 0.0 & 0.0 \\
\hline 2014 & 0.0 & 0.0 & 0.0 & 0.0 \\
\hline 2015 & 0.0 & 0.0 & 0.0 & 0.0 \\
\hline
\end{tabular}

The values outside and inside of parentheses are the total and daily mean of observed data, respectively. ${ }^{a}$ Measured values taken from the conventional plots (labeled as LA/LV-S1,S2, LA/LV-S). ${ }^{b}$ Measured values taken from the bare plots (labeled as LA/LV-B). ${ }^{c)}$ Measured values taken from the zeropercolation plots (labeled as LA/LV-Z). ${ }^{d}$ Measured values taken from the foliage application plots (labeled as LA/LV-F). 


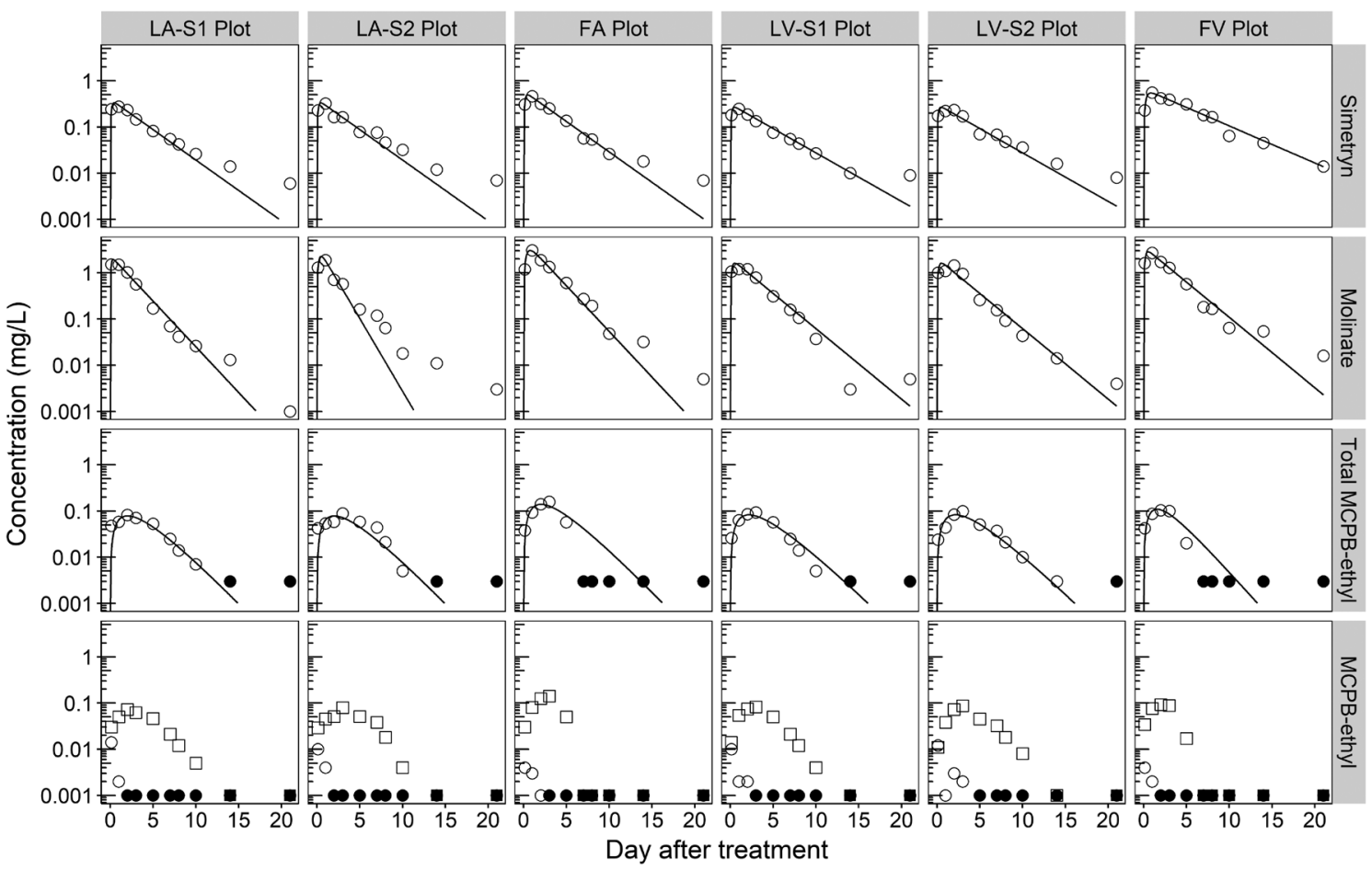

Fig. 3. Analytical and simulated concentrations of pesticide in paddy water for lysimeters and paddy fields in 2012. ( () ) and $(\square)$ analytical concentration of the parent and the metabolite (the closed symbol means "<LOQ"), respectively; (-) simulated concentrations by the kinetic model.

FA plot. Additionally, the interannual variations of daily percolation rates were considerable in the FA plot. These differences could be associated with the mechanical mixing of paddy soil, such as the puddling. Adachi reported that puddling is sensitive to reductions in the daily percolation rate of alluvial soils and less sensitive to that in volcanic soils. ${ }^{21)}$ In 2012, two unintentional drainage events were observed at 9 and 11 DAT in both paddy fields due to intensive rainfalls. The amounts of drained water at 9 and 11 DAT were 4.8 and $1.7 \mathrm{~cm}$ in the FA plot and 4.0 and $2.0 \mathrm{~cm}$ in the FV plot, respectively.

\section{Pesticide dissipation in lysimeters and paddy fields}

\subsection{Analytical results in 2012}

The analytical concentrations of three herbicides, including one metabolite, in paddy water applied in 2012 are shown in Fig. 3. From the analytical results, the dissipation ratio that quantifies the decrease achieved in the concentration in paddy water was calculated as

$$
\text { Dissipation ratio }=\left(1-\frac{C_{21-\mathrm{DAT}}}{C_{\mathrm{obs}-\mathrm{max}}}\right) \times 100
$$

where $C_{21-\mathrm{DAT}}$ is the analytical concentration at 21 DAT and $C_{\text {obs-max }}$ is the maximum analytical concentration. Similarly, the relative maximum concentration $\left(C_{\text {rmax-obs }}\right)$, defined as

$$
C_{r \max -\mathrm{obs}}=\frac{C_{\text {obs-max }}}{C_{\max }} \times 100
$$

was calculated. The dissipation ratio, $C_{\text {rmax-obs }}$ and the day of
$C_{\text {obs-max }}$ detected are summarized in Supplemental Table S8. All herbicides at all test plots indicated that $C_{\text {obs-max }}$ occurred within 3 DAT. MCPB-ethyl concentrations rapidly decreased within one or two days and MCPB concentrations subsequently increased. The $C_{\text {rmax-obs }}$ s were $26-62 \%, 25-62 \%$, and $17-33 \%$ for simetryn, molinate, and total MCPB-ethyl, respectively. For the differences between the lysimeters and paddy fields, the relative maximum concentrations in the paddy fields were 1.9-3.0 and 1.1-3.3 times higher than those in the lysimeters for alluvial and volcanic ash soils, respectively. During the experimental period, dissipation ratios of all pesticides were $96-100 \%$. The total MCPB-ethyl concentrations in the lysimeters decreased below the LOQ levels at 14 to 21 DAT, and those for the paddy fields both decreased below the LOQ levels at 7 DAT.

\subsection{Analytical results in 2014}

The analytical concentrations in paddy water of six herbicides, including one metabolite applied as two granular products in 2014 are shown in Fig. 4 and the dissipation ratio, the $C_{\text {rmax-obs, }}$, and the day $C_{\text {obs-max }}$ was detected are summarized in Supplemental Table S9. The $C_{\text {obs-max }}$ of six herbicides at individual test plots were detected within 5 DAT. The $C_{\text {rmax-obs }}$ s for imazosulfuron, total bromobutide, daimuron, fentrazamide, dimethametryn, and pretilachlor were $52-114 \%, 7-49 \%, 4-31 \%, 6-21 \%$, $23-43 \%$ and $30-51 \%$, respectively. Comparing the lysimeters and paddy fields, the $C_{\text {obs-max }}$ in the paddy fields were $0.93-5.2$ times greater those of the lysimeters. At 21 DAT, the dissipation ratios of target herbicides became $38-100 \%$ for the lysimeters and $96-100 \%$ for the paddy fields. Although faster dissipations 


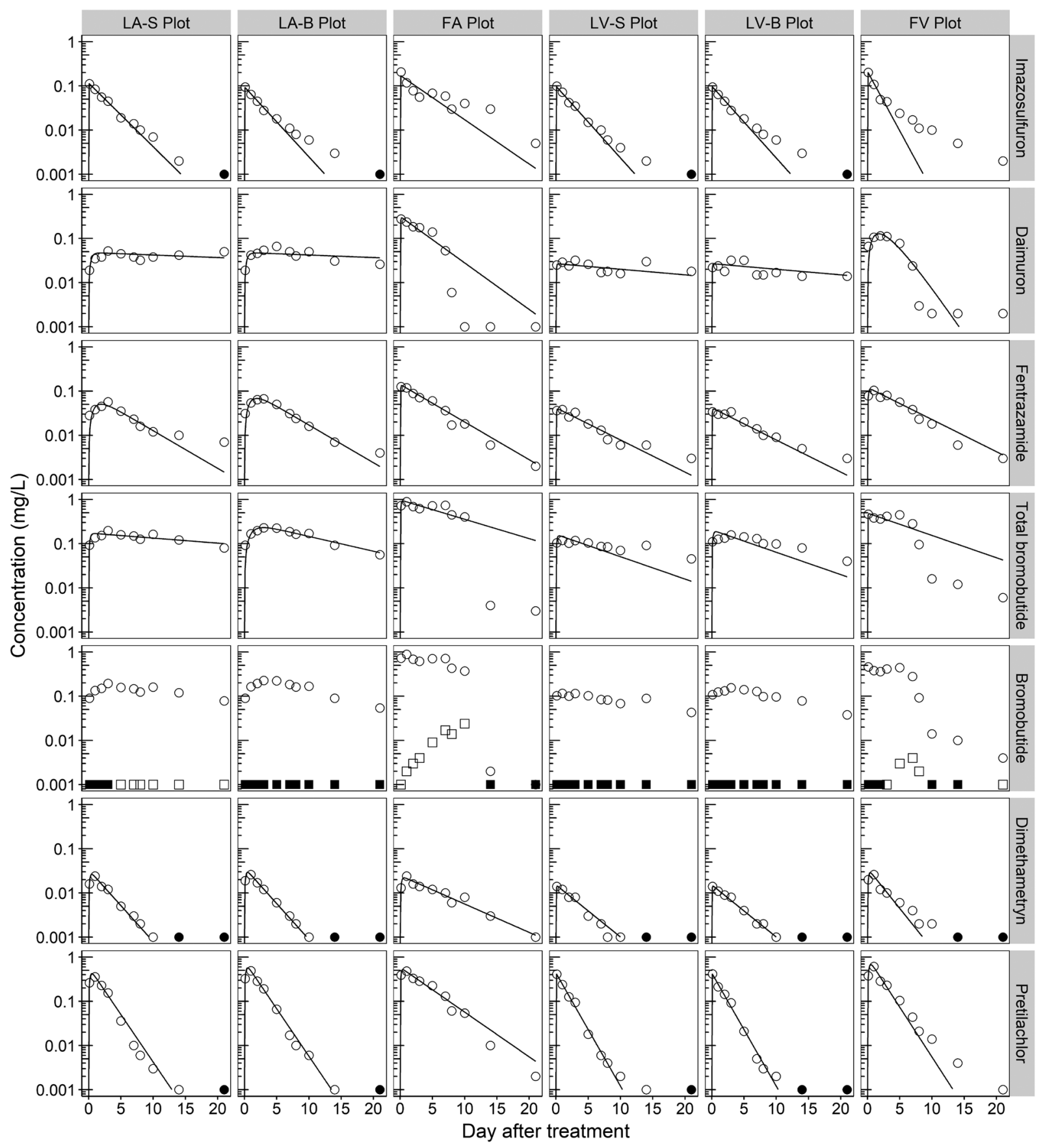

Fig. 4. Analytical and simulated concentrations of pesticide in paddy water for lysimeters and paddy fields in 2014 . ( $\bigcirc)$ and ( $\square$ ) analytical concentration of the parent and the metabolite (the closed symbol means "<LOQ"), respectively; ( - ) simulated concentrations by the kinetic model.

were found for imazosulfuron, pretilachlor, and dimethametryn in the alluvial soil plots in the lysimeters, the dissipations for total bromobutide and daimuron were slower than those of the paddy fields. In the lysimeters, bromobutide-desbromo, the metabolite of bromobutide, was detected only at the LA-S plot at LOQ levels at 5 DAT. However, the bromobutide-desbromo concentrations at the FA and FV plots increased from 0.125 and 3 DAT and were below the LOQ levels at 14 and 10 DAT, respectively.

\subsection{Analytical results in 2015}

Figure 5 shows the analytical concentrations in paddy water of insecticide, fungicide, and five herbicides, including two metabolites, applied as three granular products, and the dissipation ratio, $C_{\text {rmax-obs }}$, and the day of $C_{\text {obs-max }}$ detected are summarized in Supplemental Table S10. The concentrations of dinotefuran and total orysastrobin reached $C_{\text {obs-max }} \mathrm{s}$ within 1 DAT and their dissipation ratios were $87-100 \%$. The $C_{\text {rmax-obs }}$ of dinotefuran and total orysastrobin were $66-102 \%$ and $40-82 \%$, 


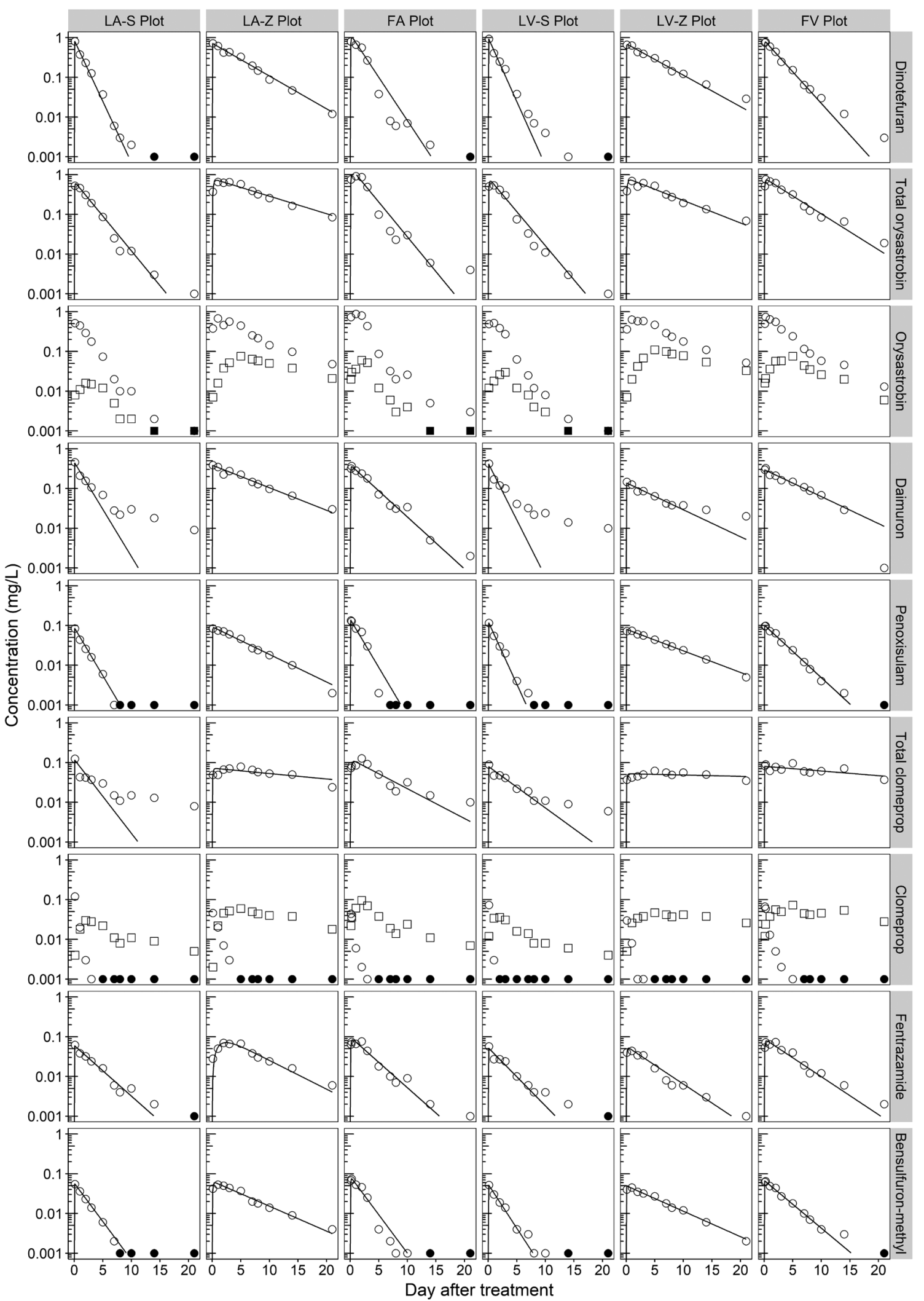

Fig. 5. Analytical and simulated concentrations of pesticide in paddy water for lysimeters and paddy fields in 2015 . ( $\bigcirc)$ and ( $\square$ ) analytical concentration of the parent and the metabolite (the closed symbol means " $<$ LOQ"), respectively; (-) simulated concentrations by the kinetic model. 


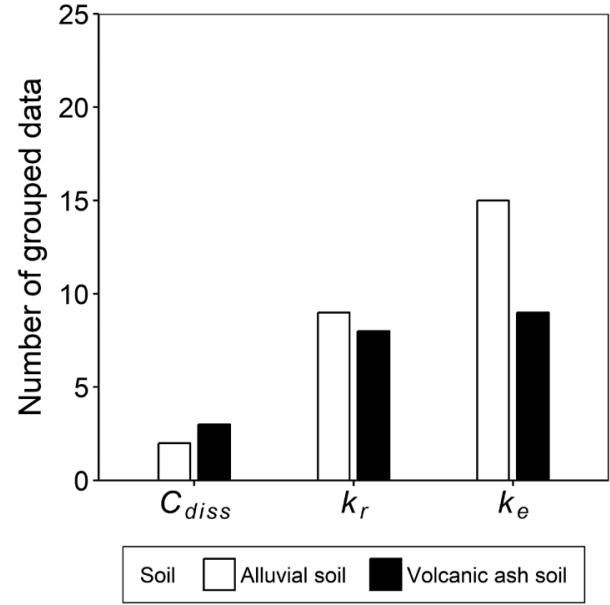

Fig. 6. Grouped data for pesticides between lysimeters and paddy fields on parameters based of the SFOR model; $C_{\text {diss }}$ is the dissolved concentration of pesticide, $k_{r}$ is the release rate from the granule, and $k_{e}$ is the decrease rate in the paddy water.

respectively. (5Z)-orysastrobin, the metabolite of orysastrobin, was detected in all of the test plots from 0.125 DAT and at maximum concentrations of $3-17 \%$ of those of the parent compound at 2 to 5 DAT. However, the $C_{\text {obs-max }} \mathrm{s}$ of target herbicides were observed at 0.125 to $5 \mathrm{DAT}$ and the dissipation ratios became $44-100 \%$ at 21 DAT. The $C_{\text {rmax-obs }}$ s of daimuron, penoxsulam, total clomeprop, fentrazamide, and bensulfuron-methyl were in range of $7-23 \%, 62-112 \%, 7-14 \%, 7-13 \%$, and $44-73 \%$, respectively. Similarly to MCPB-ethyl, clomeprop rapidly decreased to below the LOQ level within a week at all test plots. Simultaneously, clomeprop metabolite B, targeted as the metabolite of clomeprop, was detected from 0.125 DAT and moderately fluctuated throughout the experimental periods. Although the maximum difference of $C_{\text {rmax-obs }}$ between the lysimeters and paddy fields in 2015 was about 2 times, the extent of these differences was relatively smaller than that in previous years (see Supplemental Table S10). The dissipation patterns of daimuron in the lysimeters in 2015 were totally different from those of the previous year and similar to those of the paddy fields. Comparing the LA/LV-S and LA/LV-Z plots, the $C_{\text {rmax-obs }}$ for the latter tended to be lower without many exceptions and the detection time of $C_{\text {obs-max }} \mathrm{s}$ of several pesticides was especially delayed especially, for total clomeprop and fentrazamide. Overall, the order of decrease of the concentrations in the test plots was LA/LV-S, FA/ $\mathrm{FV}$, and LA/LV-Z plots.

\section{Results of kinetic analyses}

A total of 96 datasets were analyzed using the SFOR model and the results of all target pesticides at individual test plots are summarized in Supplemental Table S11. The results of the grouping analyses between the lysimeters with the same soil type conducted on the datasets of LA/LV-S1 vs. LA/LV-S2 in 2012, LA/ LV-B vs. LA/LV-S in 2014 and LA/LV-S vs. LA/LV-Z in 2015 are summarized in Supplemental Table S12. The results in 2012 and
2014 showed that three and seven of nine pesticides (10 of 18 in total) showed no differences regarding $C_{\text {diss }}, k_{r}$ and $k_{e}$ (entire grouping) in the alluvial soil and volcanic ash soil, respectively. Significant differences $(p<0.05 \%)$ were mostly observed with respect to $C_{\text {diss }}$ for pesticides that failed in the entire grouping. Among them, only two datasets showed a significant difference of $k_{e}$. For the dataset in 2015, no pesticide was entirely grouped mainly because of a significant difference of $k_{e}$.

The above constructed models updated by the grouping analysis for the lysimeter datasets, other than the LA/LV-Z plots, were subsequently compared to the corresponding datasets of the FA/FV plots with respect to the individual parameters; these results are summarized in Fig. 6 and Supplemental Table S13. Among the 25 comparisons total, although $60 \%$ of the datasets between the lysimeters and the paddy fields for the alluvial soil plots succeeded the grouping with respect to $k_{e}$, those for volcanic ash soil plots were $<40 \%$. However, for $C_{\text {diss }}$ and $k_{r}$ characterizing increased concentration and the maximum simulated concentration $\left(C_{\text {sim-max }}\right)$, the groupings of $C_{\text {diss }}$ mostly failed, whereas grouped $k_{r}$ numbered approximately $30 \%$ of the total comparisons. No clear difference regarding soil types was observed in the groupings of $C_{\text {diss }}$ and $k_{r}$. Consequently, the total grouped parameters of $C_{\mathrm{diss}}, k_{r}$, and $k_{e}$ between the lysimeters and the paddy fields for both soil types were $10 \%, 34 \%$ and $48 \%$, respectively.

The fitted results of post-grouping analyses were used as the final models and then subjected to evaluation of the model performance and the dissipation characteristics of target pesticides. The concentration curves predicted by the final models for target pesticides at individual test plots in 2012, 2014, and 2015 are superposed onto the analytical concentrations shown in Figs. 3, 4 , and 5 , respectively. Table 4 shows a statistical summary of the $\chi^{2}$ error value calculated from fitted results of the SFOR model. The number of test plots with a $\chi^{2}$ error value $\leq 15 \%$ was 60 of 96 analyses. Although the remaining 36 analyses showed a $\chi^{2}$ error value $>15 \%$, the mean and median $\chi^{2}$ error values were both $>15 \%$ ( 14.1 and $12.8 \%$, respectively). From these results, the SFOR model has the capability to simulate the dissipation of pesticides in paddy water under granule application. The estimated $D T_{50}$ varied annually. In 2012, the estimated $D T_{50}$ ranged from 1.0-3.8 days, and no apparent difference was observed regarding the experimental facilities or soil types. Comparatively, in 2014, the estimated $D T_{50}$ for the lysimeters fluctuated highly

Table 4. Summary of calculated $\chi^{2}$ error $^{a)}$

\begin{tabular}{lc}
\hline \multicolumn{1}{c}{ Measure } & Value \\
\hline Mean & $14.1 \%$ \\
Median & $12.8 \%$ \\
Minimum & $37.4 \%$ \\
Maximum & $3.2 \%$ \\
Number below 15\% & 60 \\
\hline
\end{tabular}

a) Total number of analyzed data is 96. 
(1.2-51.9 days), and faster dissipations were observed in the paddy fields for both soils (1.1-7.0 days). However, the estimated $D T_{50} \mathrm{~s}$ for the LA/LV-S plots (0.9-2.9 days) were similar to or faster than those for the FA/FV plots in 2015 (1.2-25.6 days). The estimated $D T_{50}$ s for LA/LV-Z plots were approximately $1.5-$ 5.8 times longer than those for LA/LV-S plots, except for total clomeprop, which had a much longer $D T_{50}$ (13.6 and 31.1 times in LA-S and LV-S plots, respectively).

\section{Discussion}

\section{Dissipation characteristics of granular pesticides}

From the visual assessments of the observed and simulated results shown in Figs. 3, 4, and 5, the dissipations of applied pesticides could be described mostly by first-order kinetics for both the release and decreasing phases of the concentrations in paddy water. Furthermore, the rates of the decreasing phase for several pesticides (molinate, imazosulfuron and daimuron in 2015 and total clomeprop) became slower at around 5 to 10 DAT (observed data placed above simulated lines), and sudden decreases were observed for the concentrations of total bromobutide and daimuron at the FA/FV plots in 2014. According to Ishii et al., ${ }^{22)}$ the former phenomenon was caused by the disappearance of the fast dissipation process that presented with the slow dissipation process simultaneously at first and was attributed to desorption from the paddy soil. ${ }^{22,23)}$ This biphasic dissipation was observed both in the lysimeters and the paddy fields regardless of soil type. For the latter sudden concentration decrease, a similar result was reported by Morohashi et al. ${ }^{24)}$ who concluded that the cause of this phenomenon was the drainage of paddy water. In the present study, no drainage event was observed in 2014; therefore, other processes such as the facilitation of adsorption into the soil or degradation followed by a relatively slow release phase after application might be considered (for detailed discussion, see the next section).

As reported in Section 2 of the results, the time to reach $C_{\text {obs-max }} \mathrm{s}$ varied, even for pesticides in the same formulation product or the same pesticide in different formulation products. In the SFOR model, this is because the maximum concentration levels for the granular pesticides in paddy water are dependent on the parameter of $k_{r}$, which lea to larger differences between $C_{\text {diss }}$ and $C_{\text {sim-max }}$ (or $C_{\text {obs-max }}$ ) as $k_{r}$ became smaller. ${ }^{25)}$ In our data, the detection ratio of $C_{\text {sim-max }}\left(C_{\text {sim-max }} / C_{\text {diss }} \times 100\right)$ was in a range of $36-100 \%$ for $C_{\text {diss }}$ s and that of the $C_{\text {obs-max }}$ was $37-$ $138 \%$. Although 59 of 96 datasets of the calculated ratios were close to $C_{\text {diss }}(\geq 90 \%)$, considerable differences $(<50 \%)$ were observed in seven datasets, of which $C_{\text {obs-max }}$ was detected after 1 DAT. Care must be taken when estimating the in-field partitioning ratio $\left(K_{\mathrm{d} \text {-field }}\right)$ between paddy water and soil from the observed concentration of such datasets, which could lead to overestimating the $K_{\mathrm{d} \text {-field }}$. $K_{\mathrm{d} \text {-field }}$ is useful for assessing the state of equilibrium by comparing the laboratory $K_{d}$ estimated from the batch equilibrium test. ${ }^{24,26)}$
2. Factors affecting experimental performance of lysimeters and paddy fields

\subsection{Hydrological variabilities}

As reported in Section 3 of the results, the lysimeter experiment could simulate close to half of the decrease phases of pesticide concentrations in the actual paddy fields by the groupings of $k_{e}$. Nevertheless, the groupings of $C_{\text {diss }}$ between the lysimeters and fields mostly failed because the paddy fields tended to show higher concentrations than the lysimeters. Nhung et al. ${ }^{9)}$ reported that the maximum concentrations of simetryn and thiobencarb in an experimental paddy field were higher than those simulated by micro paddy lysimeters by factors of 2.1 and 2.9 at the maximum, respectively, although the daily water management was excellently mimicked. One possible cause was that the uniformities of the initial hydrological conditions in actual paddy fields, where it is technically difficult to adjust the paddy water depth to exactly $5 \mathrm{~cm}$ because of the larger area than that of lysimeters (see Supplemental Fig. S2). During experiments, the $C_{\text {rmax-obs }}$ s of imazosulfuron at the FA and FV plots in 2014 and dinotefuran and penoxsulam at the FA plots in 2015 exceeded the $C_{\max }$ s. These pesticides were water soluble and exhibited relatively low soil adsorptivity, so they might be the most susceptible to fluctuations of water balance components among the test pesticides (see Supplemental Table S3). On the day when the $C_{\text {obs-max }}$ was detected ( 0.125 or $\left.0.250 \mathrm{DAT}\right)$, while the observed water depths at twelve points of the FA plot in 2014 could not be observed because of high turbidity, those of the FA plot in 2015 and the FV plot in 2014 were in a range of $3.0-4.8 \mathrm{~cm}$ and $2.5-5.9 \mathrm{~cm}$, respectively. Therefore, it is evident that the water depths in the fields were spatially less uniform and total volumes of paddy water where the formulation could be dissolved might be $<5 \mathrm{~cm}$ ponding depth although the observed water depths on the day of application fluctuated highly.

Another possible cause was meteorological covariates, such as water temperature and wind. Inao and Kitamura ${ }^{27)}$ demonstrated that the dissolution rate of molinate in granular formulation became faster as water temperature increased. In addition, the decrease rate in paddy water would be affected by the temperature variation. Ok et al. ${ }^{28)}$ reported that the $D T_{50} \mathrm{~s}$ of butachlor and pyrazosulfuron-ethyl in paddy water tested in the summer crop season were faster than those tested in the summer. Meanwhile, Motoki and Iwafune ${ }^{29}$ found that the time-dependent increase in $K_{d}$ of flutolanil became higher as the incubation temperature increased. In 2012 and 2014, the average water temperatures in paddy fields were $2.5-6.0^{\circ} \mathrm{C}$ higher than those in the lysimeters, whereas the average water temperatures in both the lysimeters and paddy fields were similar in 2015 (see Supplemental Table S6). Although the lysimeters were affected by strong winds only in 2015 , both of the paddy fields were affected by strong winds in 2012 and 2015 . The strong wind would facilitate the physical mixing of paddy water and thermal convection. ${ }^{30)}$ From these annual differences, it can be deduced that the dissipation of the granular pesticide in paddy water became faster released and decreased faster with higher detection levels as 
the water temperature became higher. The differences in detection patterns for daimuron and total bromobutide in 2014, and those for daimuron and fentrazamide in 2014 and 2015 could be explained by the two aforementioned factors.

Other environmental covariates, such as $\mathrm{pH}$ and UV-B radiation are also important for the fate and transport processes of pesticides. Takagi et al. ${ }^{31)}$ reported that the variation of $\mathrm{pH}$ ranged from neutral ( $\mathrm{pH}$ 7.5) to alkaline ( $\mathrm{pH} 9.5)$ within one day. According to Watanabe and Takagi, ${ }^{23)}$ daily UV-B radiation in paddy water below the rice canopy decreased to $20-50 \%$ of the initial level with the growth of rice plants. Such daily fluctuations would affect the fates of the pesticides that indicate $\mathrm{pH}$ dependency on their physicochemical properties and generate metabolites via hydrolysis or photolysis. To account for these effects, rather than point data as reported in this study, continuously monitored data can be useful in light of the application of environmental fate modeling.

\subsection{Effect of experimental design and soil type}

In 2012 and 2014, the $D T_{50}$ s for the lysimeters were generally similar to or shorter than those in the paddy fields regardless of soil types (see Supplemental Table S11). These results might be attributed to the vertical movement of the pesticides due to higher daily percolation rates in the lysimeters. Meanwhile, in 2015, the decrease rates at the LA/LV-Z plots tended to be slower than those of the FA/FV plots (see Fig. 5). In addition, the mean plots of $D T_{50}$ at LA/LV-S, LA/LV-Z, and FA/FV plots in 2015 shown in Fig. 7 clearly indicate that the $D T_{50}$ became longer as a function of the daily percolation rate. From these results, the setting of the daily percolation rate in the lysimeter was the most important rate-limiting factor of dissipation. Our results agreed with those of Sudo et al. ${ }^{32)}$ who found that the loss via percolation was proportional to the daily percolation rate. When comparing soil types, the variations of $D T_{50}$ for volcanic ash soils became higher than those of alluvial soils as the daily percolation rate decreased. This was possibly caused by adsorption and desorption kinetics between paddy water and soil usu-

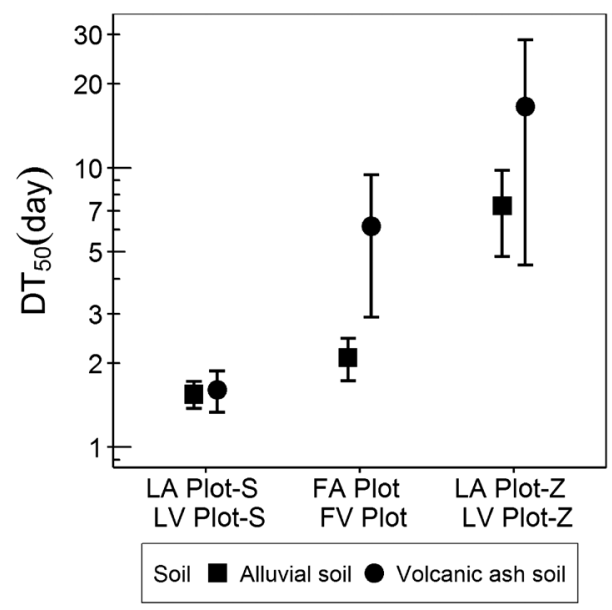

Fig. 7. Mean plot of times required for $50 \%$ dissipation $\left(D T_{50} \mathrm{~s}\right)$ for all pesticides tested in 2015 . ally masked by percolation. Considering the larger number of grouped $k_{e}$ in the alluvial soil plots (see Fig. 6), the degree of reversibility regarding adsorption-desorption phenomena might be related to characteristics of the dissipation curve. Several studies quantified the degree of reversibility regarding adsorption-desorption phenomena by the hysteresis calculated as the ratio of the Freundlich constants for adsorption and desorption. ${ }^{33,34)}$ However, since few hysteresis data of target pesticides were available, it was difficult to clarify the relationship between hysteresis and dissipation in this study.

Contrary to $k_{e}$, there was no clear difference in the number of groupings with respect to $k_{r}$ and $C_{\text {diss }}$ between the soil types in Fig. 6. However, in the whole datasets, the mean values of the $C_{\text {obs-max }}, C_{\text {sim-max }}$ and $C_{\text {diss }}$ in the lysimeter were significantly different $(p<0.05)$ from those in the paddy field for alluvial soils, whereas no significant difference was observed for volcanic ash soils. Note that since there was no significant difference in the above three parameters between the LA/LV-S and the LA/LV-Z plots in 2015, the datasets of the LA/LV-Z plots were included in the comparison of the mean. These results support the assumption that volcanic ash soils have a higher adsorption capacity (higher $K_{\mathrm{OC}}$ value) than do alluvial soils, due to a higher content of organic carbon $\left(\%_{\mathrm{OC}}\right)$, which might be an important factor in characterizing the pesticide detection pattern. However, a recent study ${ }^{35)}$ reported that the adsorption characteristics of volcanic ash soils affected not only the $\%_{\mathrm{OC}}$ but also the quality of organic carbon, so it was difficult to determine the factor affecting the difference between soil types within this study.

The disadvantage of the lysimeter experiment is that the concentration in soil cannot be monitored simultaneously during the experimental period. Therefore, it is difficult to predict the above-mentioned relationships of paddy water and soil. To overcome this, a laboratory water-sediment study could be available to help us better understand the interaction of pesticide between soil and water instantly. ${ }^{36)}$ The applications and feedback of the experiment regarding the environmental fate of pesticides between laboratory and field scales are important for improinge the lack of knowledge and optimization of the experimental design.

\section{Evaluation of experimental performance and further applica- tions}

In this study, rather than explaining the fate and transport processes of individual pesticides in depth, we comprehensively presented and analyzed the dissipation in paddy water of granular pesticides applied to lysimeters and actual paddy fields with two different soil types to extract differences and similarities between them. Our study first showed that $56 \%$ of the entire processes and about $90 \%$ of the decrease phases in the dissipation of paddy pesticides were grouped between the lysimeters tested in 2012 and 2014. In addition, the setting of the daily percolation rate was the key parameter for reducing the variability of $D T_{50}$. These results prove that the experimental performance of lysimeters is highly reproducible data under a controllable ex- 
perimental design and steady water management. Secondly, the dissipation of paddy pesticides in actual paddy fields could be reasonably simulated by lysimeters representing the actual dissipation curves of the release (34\%) and decrease rates (48\%), with an exception for dissolved concentrations (10\%). From these results, we found that the degree of reversibility regarding the adsorption-desorption phenomena was another key parameter for simulating the decrease phase of dissipation in the actual paddy field by lysimeter. However, it was difficult to cover in-field dissolved concentrations from the lysimeter experiment because of the variabilities associated with hydrological components such as water management and meteorological covariates in the actual paddy field.

Incorporating the SFOR model enables us to obtain the $D T_{50} \mathrm{~s}$ without compromising concentrations for the initial increase, although results could become statistically less accurate. However, since $D T_{50}$ s obtained by simple kinetic models included several dissipation processes (e.g., degradation, volatilization, or leaching), as well as hydrological variabilities, we could not quantitatively discuss the dissipation of pesticide based on fate and transport basis, such as the effect of drainage events in 2012. Mathematical models, such as PADDY model ${ }^{27,37)}$ and PCPF-1 model, ${ }^{15)}$ are useful for the further analysis of dissipation data when an unforeseeable event is observed the during experiment. Therefore, experiments comparing pesticide dissipations in lysimeters and paddy fields will be beneficial as fundamental knowledge needed to predict the environmental fate of pesticides in actual conditions.

\section{Acknowledgements}

This study was conducted as a part of the Continuing Research Project in compliance with the Expenditure Plan for Public Interest Purposes of the Institute of Environmental Toxicology (Corporate code: A012055).

We sincerely thank Dr. Yasuhiro Yogo, Prof. Hisashi Miyagawa, and Prof. Masahiro Natsume of the Advisory Panel on this project for their valuable suggestions, cooperation, and/or technical supports to our study.

\section{References}

1) http://www.maff.go.jp/e/data/stat/index.html (Accessed 8 Nov., 2018)

2) H. Watanabe, K. Inao, S. H. Vu, T. K. Phong, S. Ishihara, K. Takagi and J. Tournebize: "Pesticide Risk Assessment in Rice Paddies," ed. by D. Karpouzas, Elsevier, Amsterdam, pp. 167-214, 2008.

3) H. Kondoh, R. Fukuyama and A.-M. Liu: J. Environ. Chem. 11, 253266 (2001) (in Japanese).

4) T. Iwafune, K. Inao, T. Horio, N. Iwasaki, A. Yokoyama and T. Nagai: J. Pestic. Sci. 35, 114-123 (2010).

5) M. Sudo, T. Kunimatsu and T. Okubo: Water Res. 36, 315-329 (2002).

6) T. K. Phong, K. Yoshino, K. Hiramatsu, M. Harada and T. Inoue: Paddy Water Environ. 8, 361-369 (2010).

7) S. Maru: J. Pestic. Sci. 15, 385-394 (1990) (in Japanese).

8) K. Nakamura, H. Shiba and H. Hasegawa: J. Pestic. Sci. 8, 9-15 (1983) (in Japanese).

9) D. T. Nhung, T. K. Phong, H. Watanabe, T. Iwafune and D. Q. Thuyet:
Chemosphere 77, 1393-1399 (2009).

10) D. Q. Thuyet, H. Watanabe, K. Takagi, K. Yamazaki and D. T. T. Nhung: J. Pestic. Sci. 37, 20-27 (2012).

11) http://www.acis.famic.go.jp/eng/shinsei/13-3987.pdf (Accessed 8 Nov., 2018)

12) K. Kondo, Y. Wakasone, J. Okuno, N. Nakamura, T. Muraoka, K. Iijima and K. Ohyama: J. Pestic. Sci. 44, 61-70 (2019).

13) http://www.acis.famic.go.jp/eng/shinsei/8147annex.pdf (Accessed 8 Nov., 2018)

14) R. G. Allen, L. S. Pereira, D. Raes and M. Smith (eds.): "Crop Evapotranspiration-Guidelines for Computing Crop Water Requirements-FAO Irrigation and Drainage Paper 56," FAO, Rome, 1998.

15) H. Watanabe, K. Takagi and S. H. Vu: Pest Manag. Sci. 62, 20-29 (2006).

16) S. H. Vu, H. Watanabe and K. Takagi: Agric. Water Manage. 76, 195210 (2005).

17) Y. Wakasone, K. Kondo, K. Iijima, K. Ohyama, J. Okuno, N. Nakamura and T. Muraoka: Proceedings of the 33rd Environmental Pesticide Science the 38th Pesticide Residue Analysis Joint Symposium on Pesticide Science, 97-104 (2015) (in Japanese).

18) O. Richter, B. Diekkrüger and P. Nörtersheuser: "Environmental Fate Modelling of Pesticides," Wiley-VCH Verlag GmbH, pp. I-IX, 2007.

19) "Nonlinear Regression with R," ed. by C. Ritz and J. C. Streibig, Springer New York, New York, pp. 109-131, 2008.

20) FOCUS: "Guidance Document on Estimating Persistence and Degradation Kinetics from Environmental Fate Studies on Pesticides in EU Registration," Report of the FOCUS Work Group on Degradation Kinetics, EC Document Reference Sanco/10058/2005 version 2.0, 2006.

21) K. Adachi: Trans.: JSIDRE 1988, 1-8,a1(1988) (in Japanese).

22) Y. Ishii, K. Inao and Y. Kobara: Bull. Natl. Inst. Agro. Environ. Sci. 23, 15-25 (2004) (in Japanese).

23) H. Watanabe and K. Takagi: Environ. Technol. 21, 1393-1404 (2000).

24) M. Morohashi, S. Nagasawa, N. Enya, K. Suzuki, T. Kose and K. Kawata: Bull. Environ. Contam. Toxicol. 88, 521-525 (2012).

25) O. Richter, B. Diekkrüger and P. Nörtersheuser (eds.): "Environmental fate modelling of pesticides: from the laboratory to the field scale," VCH, Weinheim, New York, 1996.

26) M. Sudo, Y. Goto, K. Iwama and Y. Hida: J. Pestic. Sci. 43, 24-32 (2018).

27) K. Inao and Y. Kitamura: Pestic. Sci. 55, 38-46 (1999).

28) J. Ok, N. H. Doan, H. Watanabe, D. Q. Thuyet and J. Boulange: Bull. Environ. Contam. Toxicol. 89, 306-311 (2012).

29) Y. Motoki and T. Iwafune: JAPR J. 49, 351-357 (2016) (in Japanese).

30) S. Hanayama, T. Kasubuchi and T. Annaka: Paddy Water Environ. 7, 255-258 (2009).

31) K. Takagi, F. Fajardo, K. Inao and Y. Kitamura: Rev. Toxicol. 2, 269286 (1998).

32) M. Sudo, Y. Goto, T. Okajima, R. Horiuchi and H. Odani: J. Pestic. Sci. 37, 140-147 (2012).

33) T. Kawakami, H. Eun, M. Ishizaka, S. Endo, K. Tamura and T. Higashi: J. Environ. Sci. Health B 42, 1-8 (2007).

34) C. A. Alister, M. A. Araya and M. Kogan: J. Environ. Sci. Health B 46, 62-68 (2011).

35) Y. Motoki, T. Iwafune, N. Seike, T. Otani and M. Asano: J. Pestic. Sci. 39, 105-114 (2014).

36) T. Katagi: J. Pestic. Sci. 41, 121-132 (2016).

37) K. Inao, Y. Ishii, Y. Kobara and Y. Kitamura: J. Pestic. Sci. 26, 229-235 (2001). 